\title{
Nordeste flagelado pelos nazistas
}

\section{Northeast Plagued by Nazis}

\author{
RONALDO VAINFAS ${ }^{1}$ \\ https://orcid.org/0000-0003-0069-0374 \\ ${ }^{1}$ Universidade Federal Fluminense \\ Departamento de História \\ Campus de Gragoatá, Niteroi, RJ, 24220-900, Brasil \\ rvainfas@terra.com.br
}

Obra resenhada:

PEDREIRA, Flávia de Sá (org.). Nordeste do Brasil na Segunda Guerra Mundial. São Paulo: LCTE Editorial, 2019. 340 p.

A Segunda Guerra Mundial terminou há 75 anos. Terminou na Europa em maio de 1945, com a rendição alemã aos soviéticos após o suicídio de Hitler e no Japão em setembro, após as bombas lançadas pelos EUA, em agosto, sobre Hiroshima e Nagasaki. O Brasil passou por tudo isso. Viveu a crise da democracia liberal nos anos 1930, tempo do Estado Novo; participou da Segunda Guerra, enviando tropas para a Itália.

Mas o que aqui nos interessa é o Brasil no tempo da Segunda Guerra Mundial. Memórias de combatentes e pesquisa historiográfica reconstruíram a atuação brasileira na Itália. Elogio do alto comando dos aliados à bravura dos soldados brasileiros. Risco alto que alguns enfrentaram, depois da guerra, desmontando minas em diversos países ocupados pela Alemanha. Heróis de guerra, foram desprezados na volta ao Brasil, sobretudo a soldadesca, porque os oficiais foram condecoradíssimos. A maioria dos "pracinhas" que lutaram na Itália foram recrutados nas

Recebido: 29 jan. 2020 | Revisto pelo autor: 06 abr. 2020 | Aceito: 06 abr. 2020 http://dx.doi.org/10.1590/0104-87752020000200011

Varia Historia, Belo Horizonte, vol. 36, n. 71, p. 571-576, mai/ago 2020 
regiões Norte e Nordeste do país. A região foi sistematicamente atacada pelos submarinos alemães em 1942.

O livro organizado pela historiadora Flávia de Sá Pedreira, Nordeste do Brasil na Segunda Guerra Mundial, publicado pela LCTE Editorial em 2019, não deixa dúvida a respeito. Os ataques começaram no Sergipe, em agosto de 1942, quando o submarino U-507 afundou seis cargueiros brasileiros de diversas tonelagens que, acrescente-se, também faziam transporte de passageiros. Luiz Pinto Cruz e Lina Aras abrem o livro com texto bem documentado sobre tais ataques. Eles ocorreram entre 15 e 17 de agosto, afundando os navios Baependy, por ironia de fabricação alemã, o Araraquara, o Aníbal Benévolo, o Itagiba e o Arará. A cada navio torpedeado, pânico total na capital e até no interior. Parentes desesperados à procura de sobreviventes. Corpos despedaçados nas praias. Medo de uma iminente invasão alemã. Blackouts.

Dilton Maynard nos conta como o medo assolou Aracajú naqueles dias, com a explosão do Baependy. Os ataques prosseguiram na costa baiana, onde os alemães torpedearam outros quatro navios brasileiros. Total de desaparecidos no Sergipe e na Bahia: 612. Luana Quadros Carvalho analisa as consequências dos ataques ao litoral de Salvador: crises de abastecimento, inflação, mercado paralelo, o que atingiu sobretudo a população pobre da cidade.

É sabido que o número de navios mercantes brasileiros afundados por submarinos alemães - e também italianos - foi muito maior do que os torpedeados na costa nordestina. Mas a Segunda Guerra alcançou o Nordeste de forma implacável, antes de tudo porque os ataques ocorreram em mar brasileiro. O impacto social dos eventos foi tremendo. Como a censura do DIP levou dias para permitir a divulgação das notícias, o Nordeste vivenciou uma autêntica caça às bruxas nos primeiros dias da tragédia. Casas e lojas de estrangeiros, suspeitos de espionagem, foram vandalizadas. Quando a imprensa é censurada, predomina o boca-a boca e todo abuso se torna banal.

Seja como for, havia uma rede de espionagem alemã espalhada pelo Brasil e por outros países sul-americanos, como a Argentina e o Chile. Juliana Leite reconstrói a rede de espionagem nazista, que contava com 
cerca de dez células ramificadas em vários estados do país. A autora particulariza o caso pernambucano, onde empresas alemãs instaladas no Recife funcionavam como locais de recrutamento, a exemplo da Siemens Schukert S.A e a Dreschler \& Cia. Os grandes espiões, porém, provinham da diplomacia alemã instalada no país, e não era desconhecida das autoridades brasileiras, com sua DIP sempre atenta.

A obra em foco inclui estudos sobre várias cidades nordestinas, examinando a reação popular aos afundamentos de cargueiros brasileiros e outros aspectos da entrada do Brasil na guerra. Osias Santos Filho analisa o impulso que a guerra mundial deu à indústria têxtil maranhense. Mas, a partir de 1942, algumas atividades refluíram, como a exportação de babaçu, cujo principal importador era a Alemanha, além da carestia, inflação, racionamentos e falta de combustível. No vizinho Piauí, Clarice Lira analisa a grande mobilização popular em 1942. Não faltaram perseguições a alemães, italianos e japoneses residentes em Teresina.

A Paraíba, como expõe Daviana da Silva, foi estado dos mais destacados na mobilização do Brasil, com passeatas e comícios em Campina Grande e João Pessoa. O jornal A União publicou fotografias de paraibanos que viajavam nos navios afundados, incluindo notícia sobre a vida de cada um. A autora sugere que tais eventos despertaram não apenas um surto de brasilidade como a emergência de um sentimento de paraibanidade, assunto caro à história regional, como a de outros estados que por séculos gravitaram na órbita pernambucana. Sérgio Conceição estuda o caso de Alagoas e concentra o capítulo na história socioeconômica da região, analisando a ascensão da produção de borracha, incentivada pelo regime Vargas, vista com grande entusiasmo por algumas lideranças, criticada por outros apegados à produção de cana e de algodão.

Antônio Silva Filho examina o cotidiano de Fortaleza nos anos 1940, cidade que também abrigou base militar dos EUA, discorrendo sobre os primórdios da "americanização" de certos costumes locais. Na abertura do capítulo, uma alusão ao carnaval de rua na capital, em 1946, em especial a formação de um bloco chamado "Cordão das Coca-Colas", formado por sargentos brasileiros da FAB, que satirizava "as moças da 
sociedade local que haviam namorado soldados norte-americanos" (p.37). O autor é cauteloso na análise do tal desprezo pelas moças que "namoravam ianques", citando mesmo uma crônica de Raquel de Queiroz, datada de 1944, para quem “só os rapazes são um pouco contra os nossos aliados, rosnam bastante, falam em mentalidade colonial (das mulheres cearenses)" (p.38). Por minha conta, digo que esse bloco era tremendamente misógino e machista, conforme sugeriu, com elegância, a grande escritora brasileira.

Em obra com tal recorte regional, é certo que não poderia faltar capítulos sobre o Rio Grande do Norte, antes de tudo por causa do famoso Parnamirim Field, então distrito de Natal, hoje município autônomo, que abrigou duas bases norte-americanas nos anos 1940. Parnamirim Field não foi a única base aeronaval dos EUA no Brasil, como muitos sabem, mas era a principal, designada em mapas militares dos EUA como Trampoline of Victory porque estava na rota ofensiva dos norte-americanos nas campanhas da África e do sul da Itália. Foi nela que ocorreram os contatos mais intensos entre a população brasileira e os norte-americanos, tema que já foi objeto de estudos sérios e documentados.

A obra contém três capítulos sobre a terra potiguar. Anna Cordeiro estuda o bairro da Ribeira, em Natal, favorecido pelo boom populacional ocorrido na cidade; Luiz Gustavo Costa contribui com biografia de um natural do Rio Grande do Norte, veterano da FEB na Itália; e enfim, Flávia Pedreira contribui com trabalho sobre os intelectuais potiguares em face da base norte-americana erigida em Natal. Entre eles, Câmara Cascudo, que se mostrou ambivalente, segundo Flávia, diante da influência de Paranamirim Field sobre a cultura local: ora reconhecia o valor da "boa música" tocada pelas orquestras norte-americanas nas praças natalenses, ora depreciava a difusão de artigos como a "borracha açucarada": os chicletes.

As balizas teórico-metodológicas do livro aparecem na apresentação da organizadora. Em primeiro lugar, uma alusão ao clássico de Hannah Arendt, Origens do totalitarismo (2000), para realçar que as atrocidades do nazismo contaram com o apoio das massas. Isso é válido para a Alemanha hitlerista, e o seria para a Itália fascista e para a o regime 
stalinista na URSS. Para o Brasil não, apesar de que o regime liderado por Getúlio Vargas, após 1937, aspirava a ser um Estado fascista, do tipo definido por Mussolini: "Tudo para o Estado, nada contra o Estado, nada fora do Estado".

A historiografia brasileira, porém, com a exceção da produzida em São Paulo, qualifica o Estado brasileiro entre 1937 e 1945 como autoritário, mas não fascista, muito menos totalitário. A própria aliança do Brasil com os EUA, em 1942, contribui, factualmente, para relativizar, ou mesmo negar, a vocação fascista do Brasil na ditadura de Getúlio Vargas. Com a eclosão da guerra, em 1939, o governo permaneceu no attentisme, atento ao desenrolar do conflito, como diria o historiador francês Pierre Laborie (2010), ao caracterizar a atitude dos franceses em face da ocupação alemã. A maioria não resistiu à ocupação nazista, tampouco foi colaboracionista, senão agiu conforme as circunstâncias, transitando no que chama, com acuidade, de zona cinzenta.

Getúlio Vargas parece ter esposado o attentisme, atuando em uma zona cinzenta no campo diplomático. Muitos historiadores brasileiros preferem tratar o Estado Novo como berço do Trabalhismo, com seu viés nacionalista e popular, ao invés de assimilá-lo aos totalitarismos alemão e italiano. Nesse ponto, o paradigma teórico adotado no livro é um tanto anódino, em especial porque a imensa maioria dos textos da coletânea descreve experiências de ataques alemães ao Nordeste e sua repercussão, sem operar com o conceito. $\mathrm{O}$ totalitarismo funciona, antes de tudo, como pano de fundo histórico, em geral atribuído ao regime nazista. Mas vale dizer que, em todos os textos, os autores apontam, de várias maneiras, a contradição visceral do Estado Novo, uma ditadura inspirada nos regimes autoritários europeus, que depois se alia aos EUA na luta pela democracia no mundo.

Por outro lado, a alusão de Flávia Pedreira a Paul Ricoeur (2008) parece-me exata para exprimir as pesquisas que dão corpo ao livro. Nas palavras da organizadora, "faz-se a inclusão de entrevistas orais com aqueles que vivenciaram a época e/ou seus descendentes, trazendo à tona um verdadeiro exercício de memória que muito tem a esclarecer os fatos e personagens envolvidos" (Pedreira, 2019, p.8). Uma opção 
metodológica que atravessa todos os ensaios e nisso acerta em cheio o seu propósito.

Mas penso que não vale a pena alongar tais considerações teórico-metodológicas, por vezes nominalistas, a propósito de livro tão relevante. A história não deve, a meu ver, demonstrar teorias, senão valer-se delas para reconstruir o passado. O livro em causa faz isso à perfeição, malgrado o que afirmei acima. Vista no conjunto, a obra conta uma história do Nordeste para além das secas e da exploração da miséria, desafiando mitologias. Mostra ao vivo o Nordeste atacado pelo nazismo em 1942. Assunto fascinante e obra à altura do tema.

\section{REFERÊNCIAS BIBLIOGRÁFICAS}

ARENDT, Hannah. Origens do totalitarismo. São Paulo: Companhia das Letras, 2000.

LABORIE, Pierre. 1940-1944. Os franceses do pensar-duplo. In: ROLLEMBERG, Denise; QUADRAT, Samantha Viz (org.). A construção social dos regimes autoritários. Legitimidade, consenso e consentimento no século XX, vol. 1: Europa. Rio de Janeiro: Civilização Brasileira, 2010.

RICOEUR, Paul. A memória, a história, o esquecimento. Campinas: Editora da UNICAMP, 2008. 